\title{
Investigation of Teaching Methods of Civil Engineering Surveying Based on PDCA Mode
}

\author{
Jiansheng Shen, Wei Chen ${ }^{1 *}$, Huiyan Jia, Wenhao Zhang and Jian Gen \\ ${ }^{1}$ School of Civil Engineering and Architecture, Ningbo Tech University, 1 Qianhu road, Ningbo 315100,China. \\ Email: sjs@nit.zju.edu.cn \\ "Corresponding author. Email: chenw@nit.zju.edu.cn
}

\begin{abstract}
For the teaching problems existing in the civil engineering surveying course, the designs were carried on the teaching methods of civil engineering surveying based on the PDCA cycle mode. The teaching links of the course theory teaching, experiment and practice were fit together. Self-innovative learning model was taken into the various teaching links of civil engineering surveying course. The abilities of self-innovative learning, experimental design, practical operating, and result analysis of students were train. The problems were changed in the traditional civil engineering surveying teaching, such as the heavy theory, the light practice; imitative operation, lack of independent thinking. Through the reasonable design of teaching links, in order to improve and cultivate students' engineering practice ability and engineering innovation ability
\end{abstract}

Keywords: PDCA mode, Engineering surveying, Teaching methods.

\section{INTRODUCTION}

Civil engineering survey, as a general course of civil engineering undergraduate major, is a professional basic course that must be mastered by students with strong application[1]. It mainly studies the measurement problems in the field of construction engineering, and its task is to enable students to acquire and master the basic knowledge and measurement operation skills of engineering measurement through various teaching links of theory and practice, and to complete the measurement and measurement analysis of engineering according to the needs of actual engineering design, construction, operation and maintenance. Therefore, it is of great significance to explore and construct the course scientifically and reasonably in terms of teaching content, teaching methods, teaching means, practice links and assessment methods, so as to improve the teaching effect and quality[2].

In recent years, with the vigorous development of civil engineering majors in my country, the number of professional enrollment has increased sharply, which has made the shortage of engineering survey teaching, equipment, teachers and venues increasingly serious[3]. In the current engineering survey teaching, there are also serious problems such as the disconnection between teaching and production practice, outdated technology and so on[4,5]. Quite a number of students have low practical ability, do not understand the field measurement method, cannot use advanced instruments, cannot flexibly use measurement knowledge to solve practical problems and other phenomena[6,7]. In addition, after the implementation of the new syllabus, the classroom teaching and experimental hours are reduced, which brings new challenges to the quality and effectiveness of engineering measurement teaching [1,2]. How to improve the teaching quality and effect of civil engineering survey course under the requirements of the new syllabus is an urgent problem to be solved. Therefore, it is necessary to further carry out the teaching reform and research of this course, and explore the effective organization and implementation of theoretical teaching, experiment and practice.

\section{EXISTING PROBLEMS IN TEACHING}

At present, there are mainly the following problems in the teaching of civil engineering surveying courses:

(1)Poor pertinence. the main knowledge points of the existing survey curriculum design focus on surveying and mapping in surveying, lack of pertinence of different majors. 


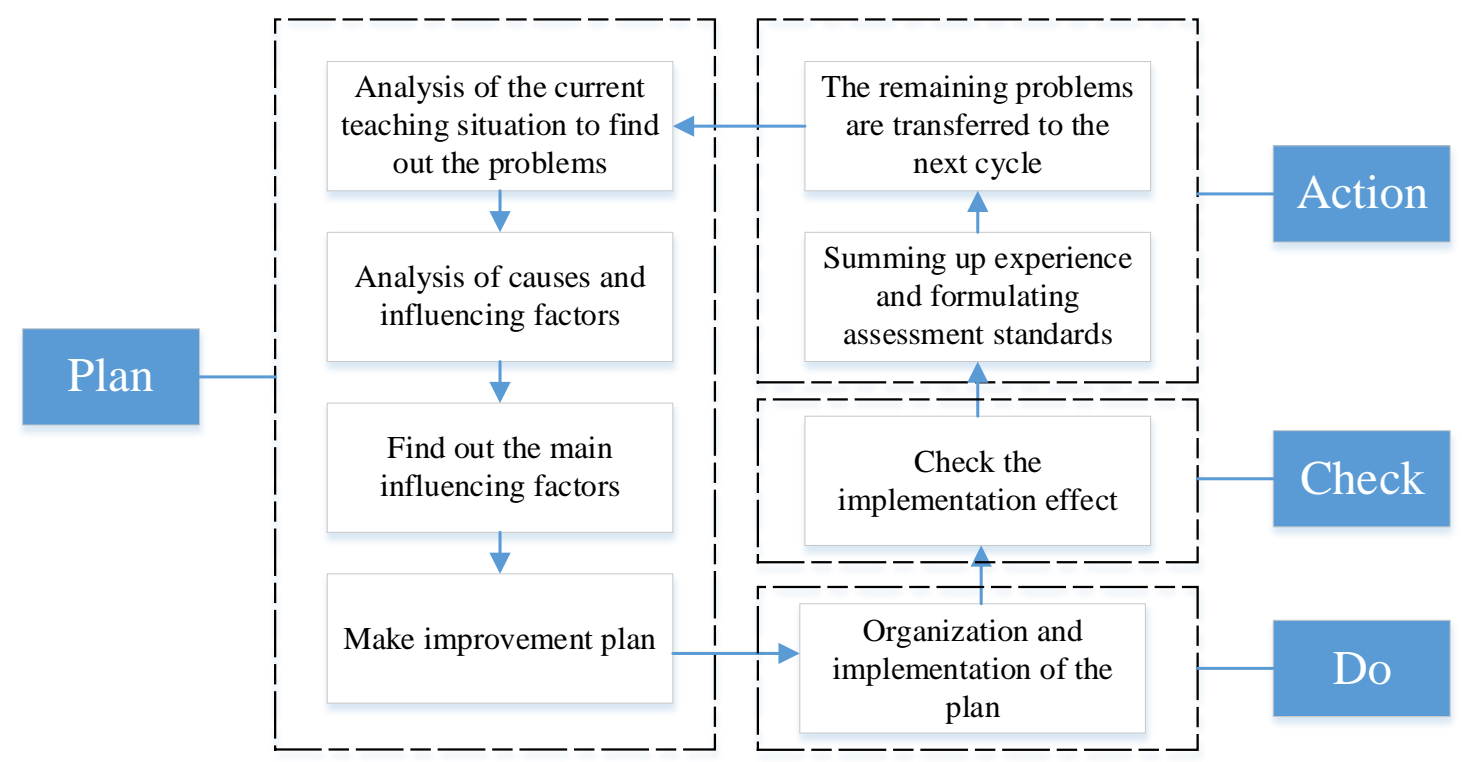

Figure 1 Roadmap of teaching methods based on PDCA cycle mode

(2)Class hours are limited. After the implementation of the new syllabus, the number of classroom teaching and experimental hours is reduced, and the theoretical teaching and production practice are basically "out of touch", the integration of the two is insufficient, and the lack of "thinking while learning theory and practice".

\section{TEACHING DESIGN OF ENGINEERING SURVEY BASED ON PDCA}

The teaching method based on the PDCA cycle model is a gradual teaching method that organically combines theoretical teaching and experimental practice. The basic process is to make a teaching plan (Plan) before the start of civil engineering surveying teaching, then put the teaching plan into practice (Do),

Teaching mode of engineering survey

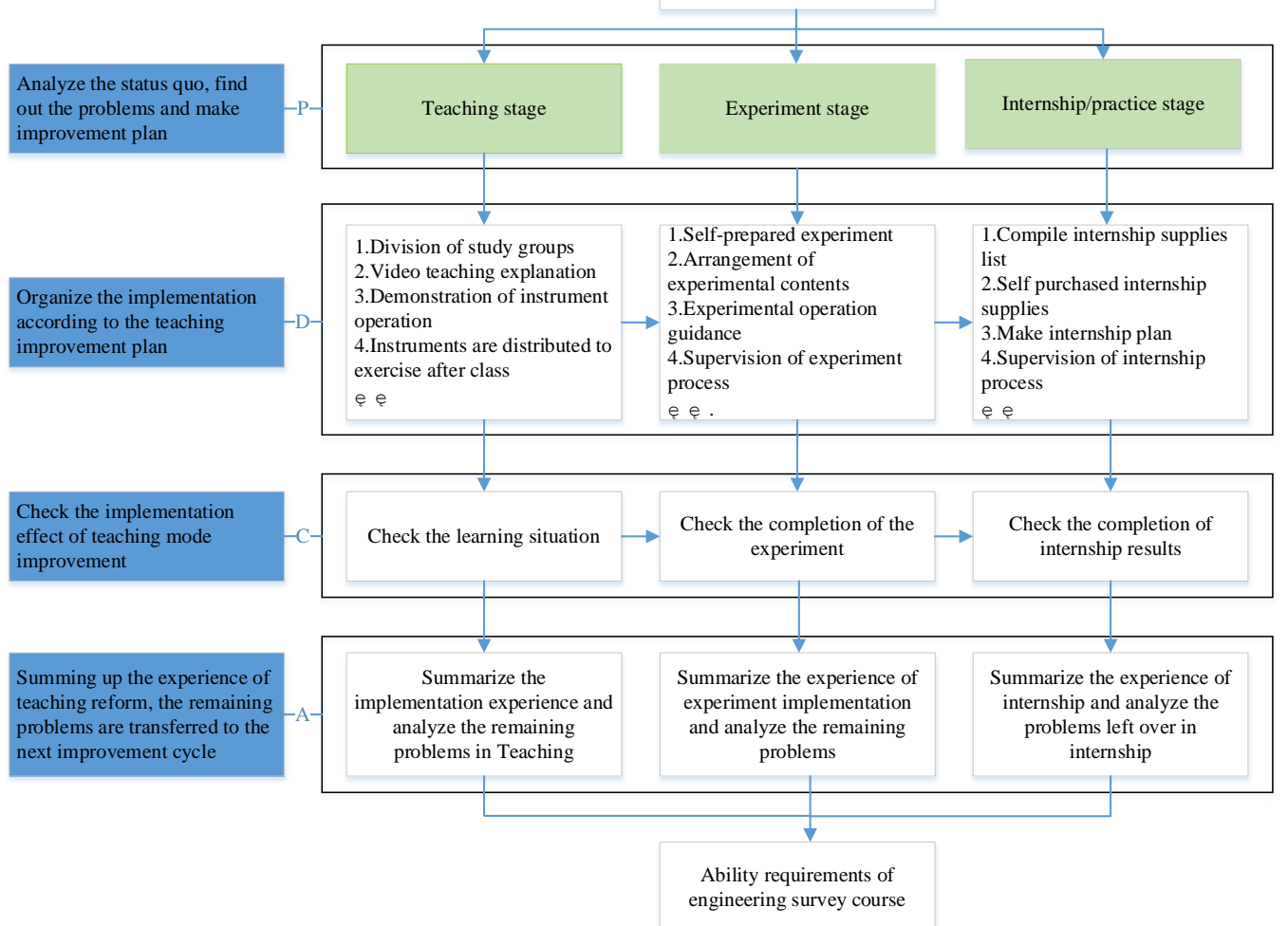

Figure 2 Design roadmap of teaching mode based on PDCA cycle 


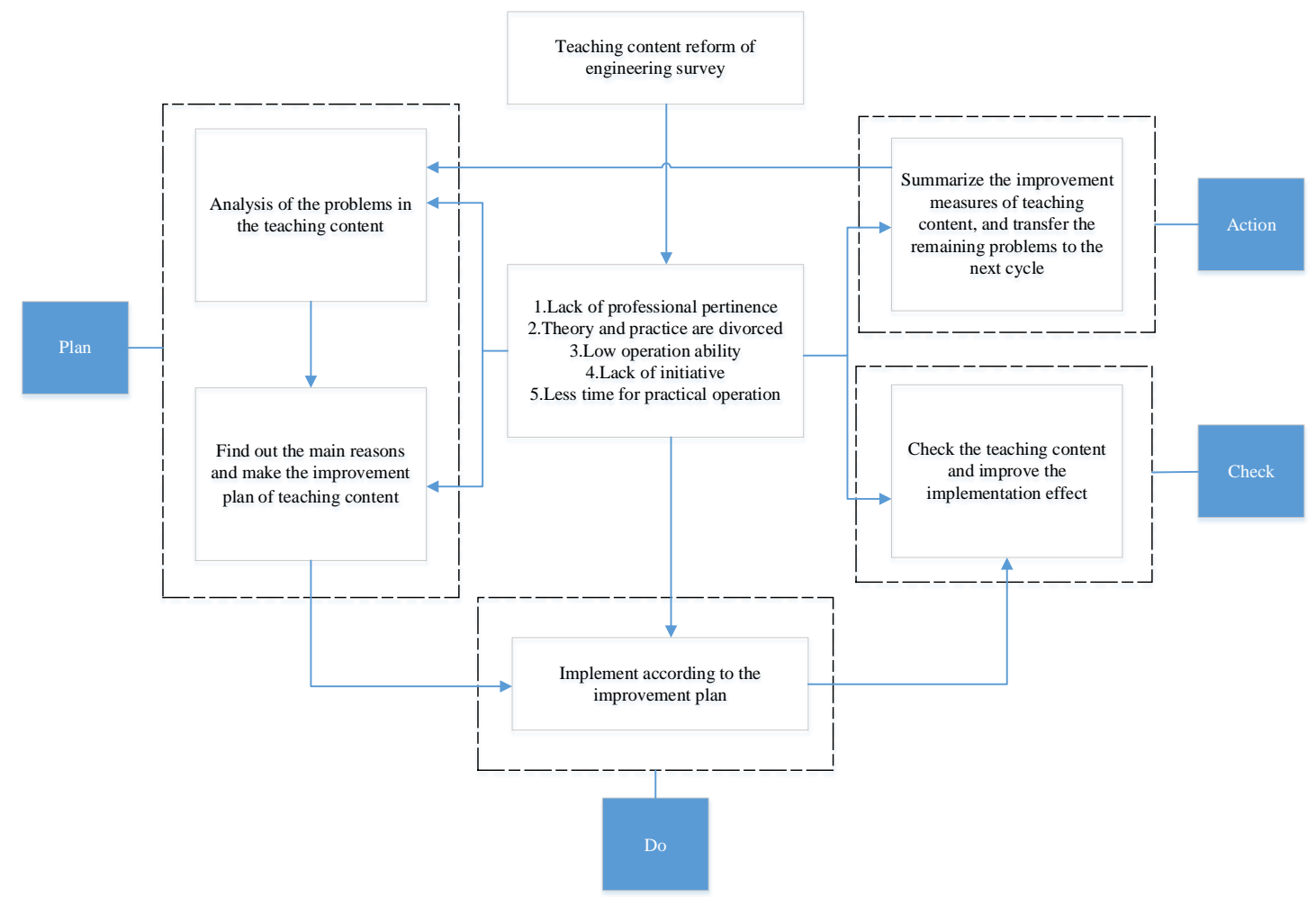

Figure 3 The design and requirement roadmap of teaching content based on PDCA cycle

then check the implementation and effect of the plan (Check), and finally deal with it according to the inspection results (Action), thus cyclically, continuously improving the teaching quality and level of engineering measurement[8].

Aiming at the main problems in the current civil engineering surveying course, a teaching method based on the PDCA cycle model is proposed, and active innovation learning is integrated into the teaching link. The specific route is shown in Fig.1. Firstly, it analyzes the problems existing in the teaching of civil engineering survey, finds out the reasons and influencing factors, and formulates the measures and plans for teaching improvement according to the main reasons and influencing factors. Organize the implementation according to the established plan, check the implementation effect, summarize the improvement experience of the teaching mode, formulate the assessment standards, and transfer the remaining problems to the next PDCA cycle for resolution.

\subsection{Design of Teaching Mode Based on PDCA}

Different from the conventional teaching mode, this paper discusses the implementation of learning experiment group division, goal and task determination (learning theme), plan making, task decomposition, experiment guidance, process monitoring and other links, so as to reflect the characteristics of "student-centered", "experimental learning", "learning in practice", "learning while doing". On the basis of the above, a relatively complete implementation guide for engineering survey teaching, experiment and practice is formulated.

The specific implementation plan of the teaching mode reform is shown in Fig.2. Aiming at the problems existing in engineering measurement theory teaching, experimental teaching, and practice teaching, the corresponding teaching mode reforms are carried out, and the corresponding learning guidance plan is set to run through the theoretical teaching and experiment, internship and practice the whole process, strengthen the connection and organic integration between all links, so that students can meet the ability requirements of the engineering measurement course.

\subsection{Design of Teaching Content Based on PDCA}

For civil engineering, road bridge and river-crossing engineering and engineering management, the teaching materials suitable for the corresponding majors are selected, and the contents of the teaching materials are adjusted and deleted. Six basic themes and four professional topics are set to further clarify the key points and difficulties of the course. In the process of surveying experiment and internship, we should design the teaching content closely combined with the specialty, and construct the engineering surveying experiment and internship content with strong specialty. On this basis, we should improve the courseware and establish the course learning website. 
Teaching content design based on PDCA cycle road map as shown in fig.3, the analysis of engineering surveying teaching content is lack of pertinence, hands-on ability is low, the lack of initiative, internship less operation time, find out main reason, formulate the corresponding improvement measures, with the arrangement of the professional pertinence engineering survey each teaching link, according to the improvement plan, check the implementation effect, finally to sum up the experiences of teaching reform and improve the legacy into the next cycle.

\section{CONCLUSION}

Based on the teaching method of PDCA cycle mode, the teaching method of civil engineering survey course is designed. Combines the teaching links of theory teaching, experiment and internship, and puts forward that active and innovative learning should be integrated into all teaching links of civil engineering surveying course. Cultivate the ability of students' autonomous learning, experimental design, practical operation and calculation result analysis, and change the traditional teaching of civil engineering surveying, which focuses on theory rather than experiment, and the practice is mainly imitative operation and lacks independent thinking.

\section{AUTHORS' CONTRIBUTIONS}

The background research for this publication was carried out by all authors. Jiansheng Shen wrote this manuscript,and Wenhao Zhang translated the manuscript.Huiyan Jia and Wei Chen reviewed this manuscript.

\section{ACKNOWLEDGMENTS}

The authors wish to acknowledge the financial support of the Ningbo Tech University (NITJG-201919), Zhejiang Provincial Laboratory Work Research Project(YB202132) and the cooperative education project of Zhejiang provincial (Reform and innovation of civil construction curriculum system based on "intelligent construction" under the background of new engineering).

\section{REFERENCES}

[1] Yu Jiayong, On the teaching reform of civil engineering surveying course $[\mathrm{J}]$. Engineering of Surveying and Mapping, 2014,vol.01, pp.78-80. DOI:10.3969/j.issn.1006-7949.2014.01.018.

[2] Wang Anyi, Chen Changping, SHEN Lu. Research and Construction of the Practical Teaching System for Engineering Survey Course[J].Geomatics \& Spatial Information Technolagy, 2014,vol.01, pp.76-78.

DOI:10.3969/j.issn.1672-5867.2014.01.022.

[3] Qin Zhenzhen. On the Practicality of "Civil Engineering Surveying"Teaching Reform[J]. Journal of Educational Institute of Jilin Province, 2014,vol.12, pp. $48-49$ DOI:10.16083/j.cnki.1671-1580.2014.12.021.

[4] Ke Xiaoxia. Research on Teaching Reform of Engineering Survey in Working Porecess[J]Hunan Agricultural Machinery, 2014,vol.08, pp.103-104. DOI:10.3969/j.issn.1007-8320.2014.08.054

[5] Guo Fanbo, Qiu Zhanhong. Research on Project Type Teaching of Engineering Survey[J]. Bulletin of Surveying and Mapping, 2014,vol.06, pp.128-130.

DOI:10.13474/j.cnki.11-2246.2014.0211.

[6] Deng Shaoyun. Research on the teaching reform of the course "Construction Engineering Surveying" based on engineering project tasks[ $\mathrm{J}]$. Heilongjiang Science and Technology Information, 2014,vol.19, pp. $249-250$

DOI:10.3969/j.issn.1673-1328.2014.19.230.

[7] Li Aimin, Yan Chaode, Wu Liancheng. Practice teaching reform of engineering survey course [J].Laboratory Research and Exploration, 2013, vol.32,

pp.324-325.DOI:CNKI:SUN:SYSY.0.2013-06-091.

[8] Wei Yong, Yu Qiang, Wu Chunbo, pan Xiu. Teaching improvement practice of engineering survey based on PDCA cycle[J]. Times Education, 2014, vol.15, pp.226-227. DOI:10.3969/j.issn.1672-8181.2014.15.165. 